\title{
Magia en el \\ Bosque- El gran \\ libro encantado. \\ Un cuento \\ musicalizado \\ para niños
}

Magic in the Forest - The grat encharted book. A musicalized tale for children

\section{MATILDE CHAVES DE TOBAR}

Escuela Hispanica de Música "Santa Marta de Tormes" Salamanca 
$\Rightarrow$ Recibido 30/12/2018

\section{Experiencias Educativas}

$\checkmark$ Aceptado 25/02/2019
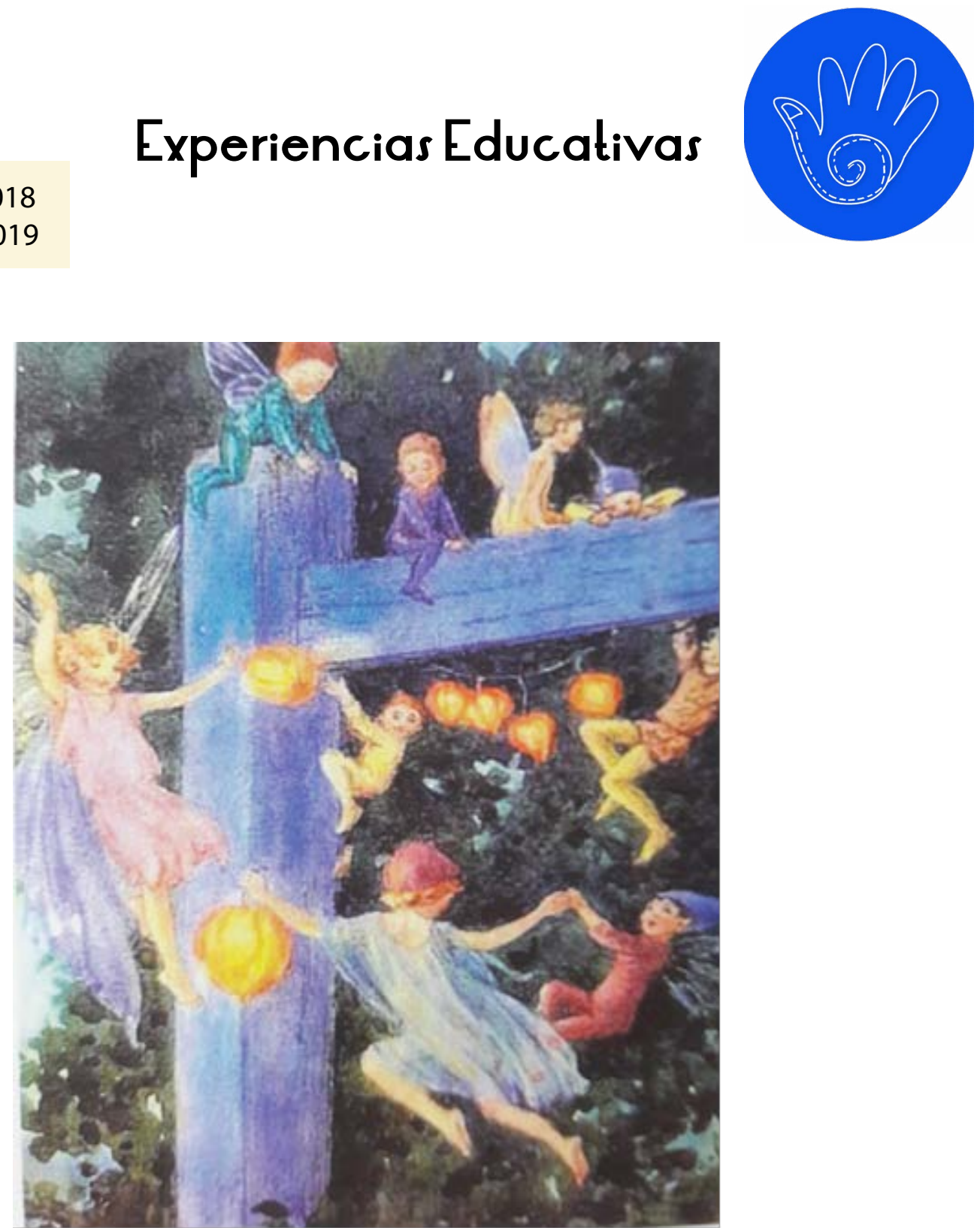

Argumento, guión y musicalización: Matilde Chaves de Tobar Ilustraciones: Matilde Chaves de Tobar

Personajes: la niña, Las hadas y los gnomos

Las hadas: de la Belleza, del amor, de la música, de la danza, de la alegría, de la bondad y de las flores

Gnomos: De la picardía, el gnomo serio, el gnomo trabajador, el gnomo del sueño, y el gnomo burlón. 


\section{Argumento}

En un intrincado bosque vivía una hermosa niñita llamada Lila; Había escuchado de sus abuelos lo que se decía de las Hadas del bosque y de sus poderes mágicos.

Una noche se adentró sola en la floresta con la intención de encontrar a aquellos seres diminutos de gran belleza y de cualidades extraordinarias.

Por el camino se tropezó con un duendecillo amable pero algo serio, que la guió en todo su viaje al fondo del bosque y le contó que las hadas que ella buscaba vivían dentro de un gran libro mágico y que entre los dos, debían encontrar ese libro y llamarlas para que ellas salieran a su encuentro.

Al descubrir el libro, la pequeña Lila, se asombró y comenzó a llamarlas, a lo que las hadas respondieron y la dotaron de muchos dones; los duendecillos responden a su llamado y aparecen al final de la historia para acompañarlas en sus juegos y en su despedida.

El narrador: Ésta es una historia maravillosa j!!

En lo más profundo del bosque la pequeña Lila, recorre el camino sin pensar en peligros, ni en miedos. De hadas y gnomos ha oído hablar a sus abuelos, de cómo cuidan de la naturaleza, de sus grandes poderes mágicos y de los dones que ofrecen a los humanos.

También, de ellas las hadas, sabemos que cuidan de los bosques, de las flores, cuidan del agua y de nuestros amigos los gnomos, que son juguetones, trabajadores, dormilones y burlones.

La noche llega y las brumas blancas y brillantes hacen nacer la luna; surgen del fondo del agua y se extienden por el bosque; las flores se juntan para tejer las alas de las hadas y al vestido de la noche, prenden piedras preciosas.

Pero el bosque guarda celosamente el gran libro mágico, donde duermen las Hadas y los gnomos vigilantes cuidan de él. 
-La niña: OH!! La noche a caído y aún no encuentro a las hadas, dónde podrán estar?

Pero no debo sentir miedo, porque ellas son buenas y hermosas!!

El narrador: Por sorpresa, un gnomo muy serio se cruza en su camino y le pregunta:

- El gnomo serio: Pero bueno, pequeña niña del bosque, ¿que haces por estos lugares, a estas horas de la noche y tan sola?

- La niña: Busco a las hadas del bosque y a sus amigos los duendecillos.

- El gnomo serio: Ah!! Buscas a las hadas? Bueno, yo te llevaré hacia ellas, pero te advierto que son muchas y viven dentro del gran libro mágico.

- La niña: ¿Un libro mágico?? ¿Y cuál es ese libro?

- El gnomo serio: Es "El gran libro de las hadas" de ahí salen en las noches para cuidar del bosque y para jugar con nosotros los duendecillos a la luz de la luna.

- La niña: Y cómo podré encontrarlas?

- El gnomo serio: Solo debes desear que ellas salgan y llamarlas, pero te digo que son muchas. Ah ¡! Las hay de La belleza, del amor, de la música, de la danza, de la alegría, de la bondad, de las flores, de la salud, del agua y muchas más....

Ah!! Una cosa si te digo ¡! Ellas te pueden dar muchos dones, si tu quieres, claro está; los que tú desees j!!

- La niña: Oh!! Qué hermoso!!, bueno, pues yo quiero ser bella, quiero ser buena, quiero saber de la música y saber danzar, quiero conocer todas las flores del mundo, Ah!! y siempre quiero estar feliz!!

- El gnomo serio: Bueno, pues ven conmigo, que yo te llevaré j!! Ven conmigo j!! Vamos $j !$ - Vamos $ן !$

El narrador: El gnomo y la niña caminan por el bosque, tomados de la mano hasta encontrar el gran libro. 
- La niña: Ah! QUE GRANDE Y MÁGICO SE VE j!!!

- El gnomo serio: Si mi niña del bosque éste es y aquí viven tus hadas mágicas.

El narrador: La niña del bosque se queda sorprendida y empieza a llamar a las hadas a lo que ellas van respondiendo una a una.

(Nota: Las hadas van saliendo del libro una a una, según la niña del bosque las va llamando.)

- La niña: Hada de la belleza ¡! ¿Dónde estás???

(sale el hada de la belleza al son de la música que la acompaña)

- Hada de la belleza: Aquí estoy j!!

- La niña: $\mathrm{OH}$ ¡! Que hermosa eres ¡! (rodeando al hada en redondel y sorprendida de la belleza)

- El hada de la belleza: voy a concederte el don de la belleza, pero especialmente de la belleza espiritual!!, porque físicamente, bella ya eres desde tu nacimiento!!

(El hada de la belleza toca a la niña con su barita mágica, al son de una campanita)

- La niña: Gracias j!! Hada de la belleza j!

El narrador: Las hadas de la belleza: simbolizan la hermosura tanto física como espiritual de los humanos.

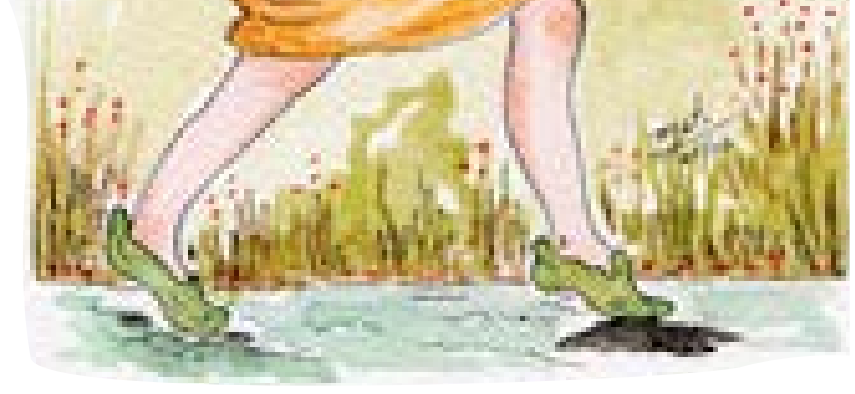

Ilustración: Matilde Chaves de Tobar
- La niña: Hada del amor!!! Dónde estás escondida?

(Sale el hada del amor, al son de la música que la acompaña) 
- Hada del amor: Aquí estoy y quiero darte el don del amor, para que siempre ames a los demás, siempre, siempre!!!

- La niña: Así lo haré ¡! Gracias hada del amor. (Y se abraza al hada del amor)

El narrador: El hada del amor simboliza el afecto en todas sus dimensiones y formas, siendo la cualidad que todos debemos tener.

- La niña: (mirando al libro y en actitud de búsqueda)

- Hada de la música j!! Que me gusta la música y tú me puedes ayudar, verdad?, dónde estás, de dónde vienes?

(Sale el hada de la música al tintineo de campanitas)

- El hada de la música: Aquí estoy y vengo de las estrellas y traigo el don de la música para que seas inmensamente feliz con los sonidos de la naturaleza, con las melodías y armonías de la música. Te regalo el don de la música j!!!

(El hada de la música toca a la niña con una batuta mágica en la mano)

El narrador: Las hadas aman la música, con sus tenues voces y sus cantos alegres y románticos se acompañan al balanceo de las flores. Sus flautas mágicas resuenan en el bosque haciendo compañía al silbido del viento.

(Aquí suena la música de la flauta y el piano y la niña y el hada de la música bailan al son de la música)

- La niña: (de manera pensativa) dice la niña al gnomo serio: A mí me gusta danzar!!

- Hada de la danza ¡!! Cómo podré danzar sin cansarme?? Dónde estás ?

(Las hadas de la danza salen del gran libro, danzando y saltando alegremente al son de la música)

- Hadas de la danza: Nosotras, las hadas de la danza vamos a concederte el deseo de bailar sin cansarte, pues el movimiento te mantendrá viva como lo estamos nosotras, míranos, que nunca descansamos!!

(Aquí, la niña empieza a danzar con las hadas al son de la música) 
El narrador: Cuentan las leyendas que ágiles como abejas bailan juntas las hadas y no hay un momento en el tiempo en que no estén dispuestas a bailar durante horas.

- La niña: Qué alegre estoy, porque por fin he visto a las hadas!!!

- La hadas de la alegría - salen saltando del libro-, : ALEGRÍA ¡! ALEGRÍA!!! Quién ha dicho La palabra ALEGRÍA j!!

- La niña: yo, yo, quiero siempre estar alegre ¡!!

- Las hadas de la alegría: Te vamos a conceder este deseo, siempre estarás alegre como nosotras, pero con una condición $\mathrm{i}$ !

- La niña: Oh, si, cuál?

- La hadas de la alegría: Que siempre debéis trasmitir a los demás vuestra alegría. La niña: Siiiiii..... (y dirigiéndose al público debe hacer reír a la gente)

Verdad que si, si ja, ja, ja....(Y todas las hadas se ríen con ella y bailan al son de la música que las acompaña).

El narrador: Con su alegría las hadas vivifican cada día nuevo, siempre contentas, siempre alegres, siempre en paz ¡!!!.

- La niña: Mirando a su alrededor dice: Oh. Cuantas flores hay por aquí, especialmente margaritas ¡! No me había dado cuenta.

- Las hadas de las flores: Saltando con sus trajes de mil colores, salen del libro y dicen: "Nosotras somos las hadas de las flores y deseamos que tú nos ayudes a cuidar de nuestras flores del bosque, porque las flores tiene en sí, todas las cualidades que te hemos dado: la belleza, el amor y el don de danzar al son del viento; Las flores nos dan alegría con sus múltiples colores."

- La niña: Abrazándose a las hadas de las flores promete fielmente que les ayudará a cuidar de las flores del bosque.

- La niña: Siii os prometo que cuidaré de las flores j!! 
El narrador: Las hadas de las flores son las criaturas más hermosas que encarnan el espíritu de las flores y los árboles. Como encarnación de todas estas cualidades que forman parte del amor y de la belleza, la margarita es una de las flores que mejor define estos sentimientos.

(Estando las hadas, junto a la niña y al gnomo, cantan la canción de "Mariposas del aire". Se debe cantar con un leve balanceo del cuerpo y tomados de las manos)

\section{Mariposas del aire}

Texto, música e ilustración: Matilde Chaves de Tobar

I

Mariposas del aire bajo la luna

Que de lindos colores surcan el cielo

En la noche callada sus cantos suenan

Con alegre caricia de balanceo

II

A las puertas del bosque la bruma blanca

Hace nacer la luna de caramelo

Y la magia en la noche abriendo paso

Teje finas las sombras de mariposas
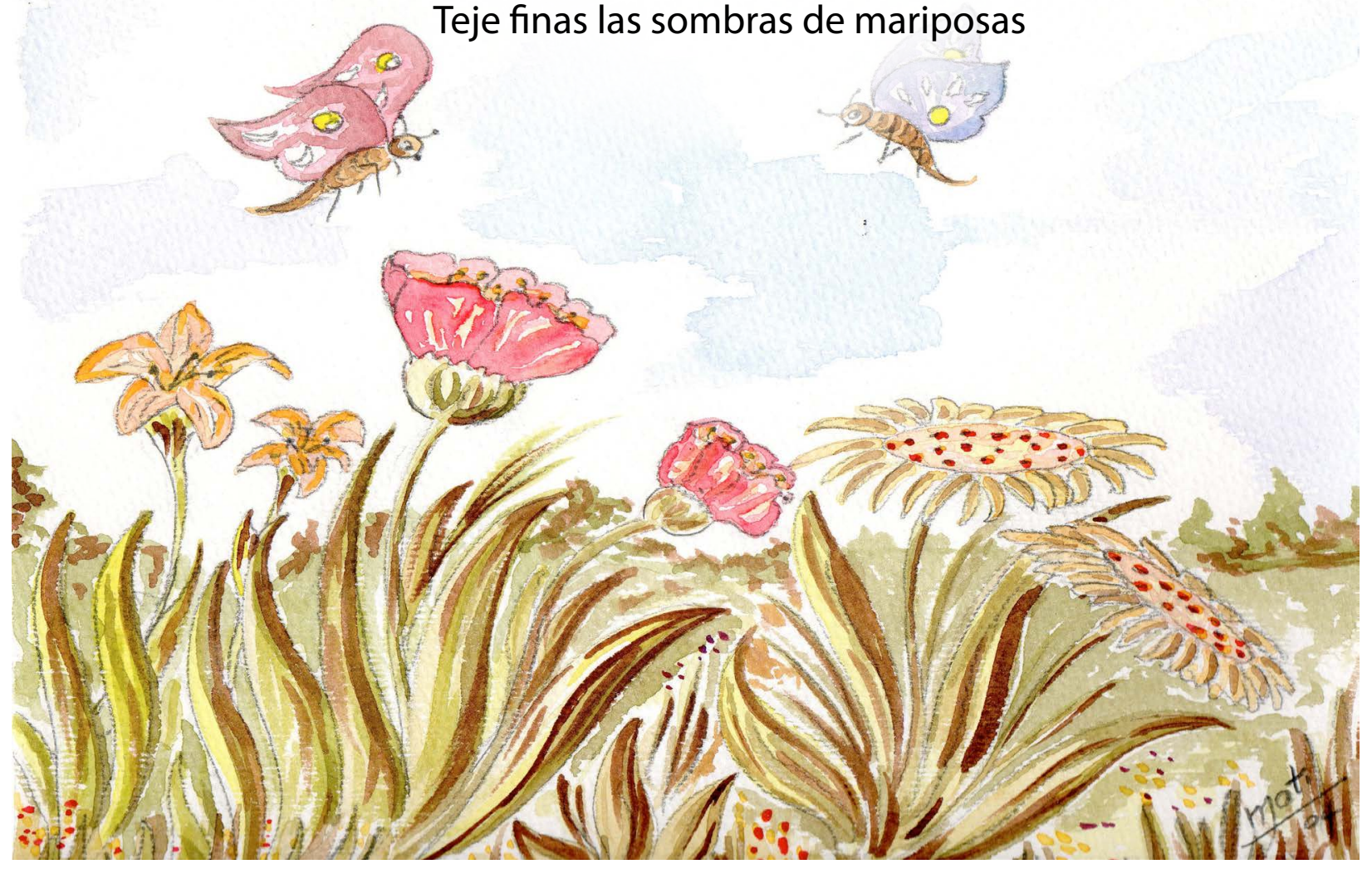
MARIPOSAS DEL AIRE

Matide Chaves de Tobar
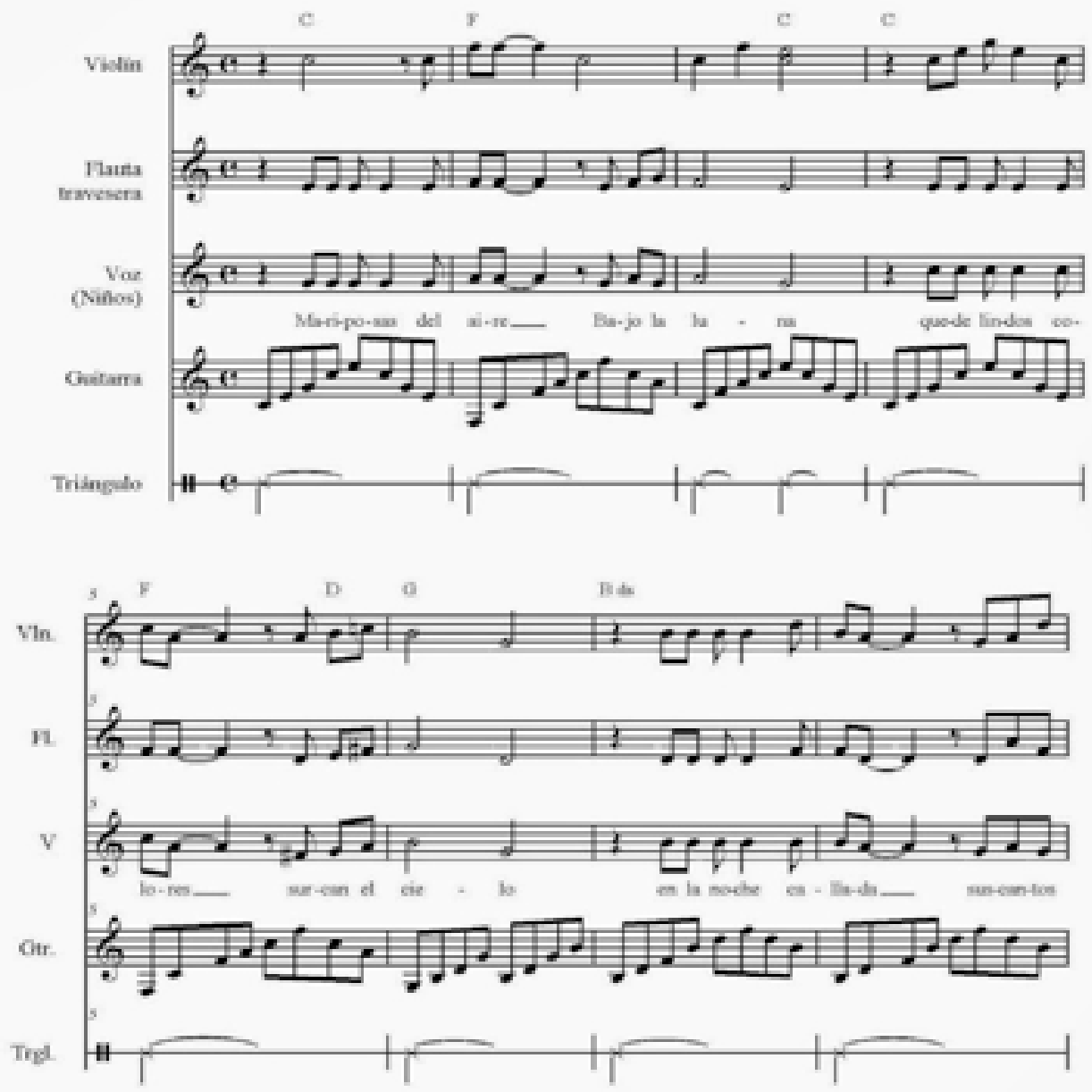

2 MARIPOSAS DEL. AIRE

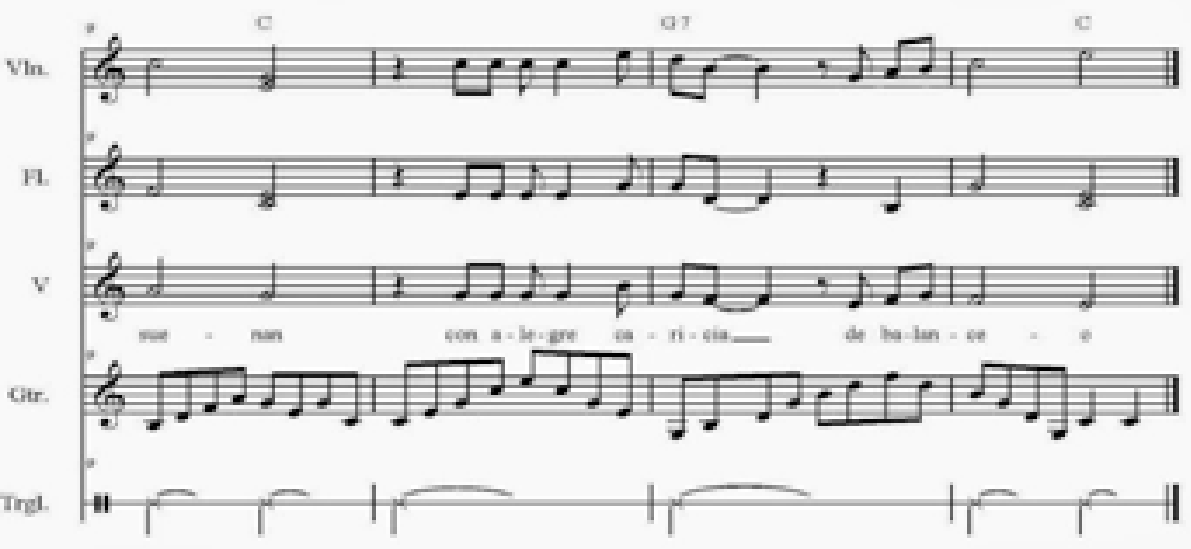

Mariposas del aire bajo la luna

que de lindos colores surcan el cielo.

en la moche callada sus cantos suenan.

con alecres cariolas de balanceo

A las puentas del bosque la bruma blance

hace nacer la luna de caramele

$Y$ la magia en la noche abriendo paso

teje finas las sombras de mariposa. 
Al terminar el canto, la niña se dirige al gnomo serio y le dice:

- La niña: Señor gnomo y dónde están los duendecillos tus amigos?? Que no los veo?

- El gnomo serio: Ah!! Es que debemos llamarlos ¡!

En éste momento las hadas, la niña y el gnomo serio, inician el canto de llamada a los duendeciIlos: (voces, piano, guitarra, clarinete y flauta" haciendo los ademanes de buscarlos, bailando al son de la música)

\section{Duendecillo}

Texto y música: Matilde Chaves de Tobar

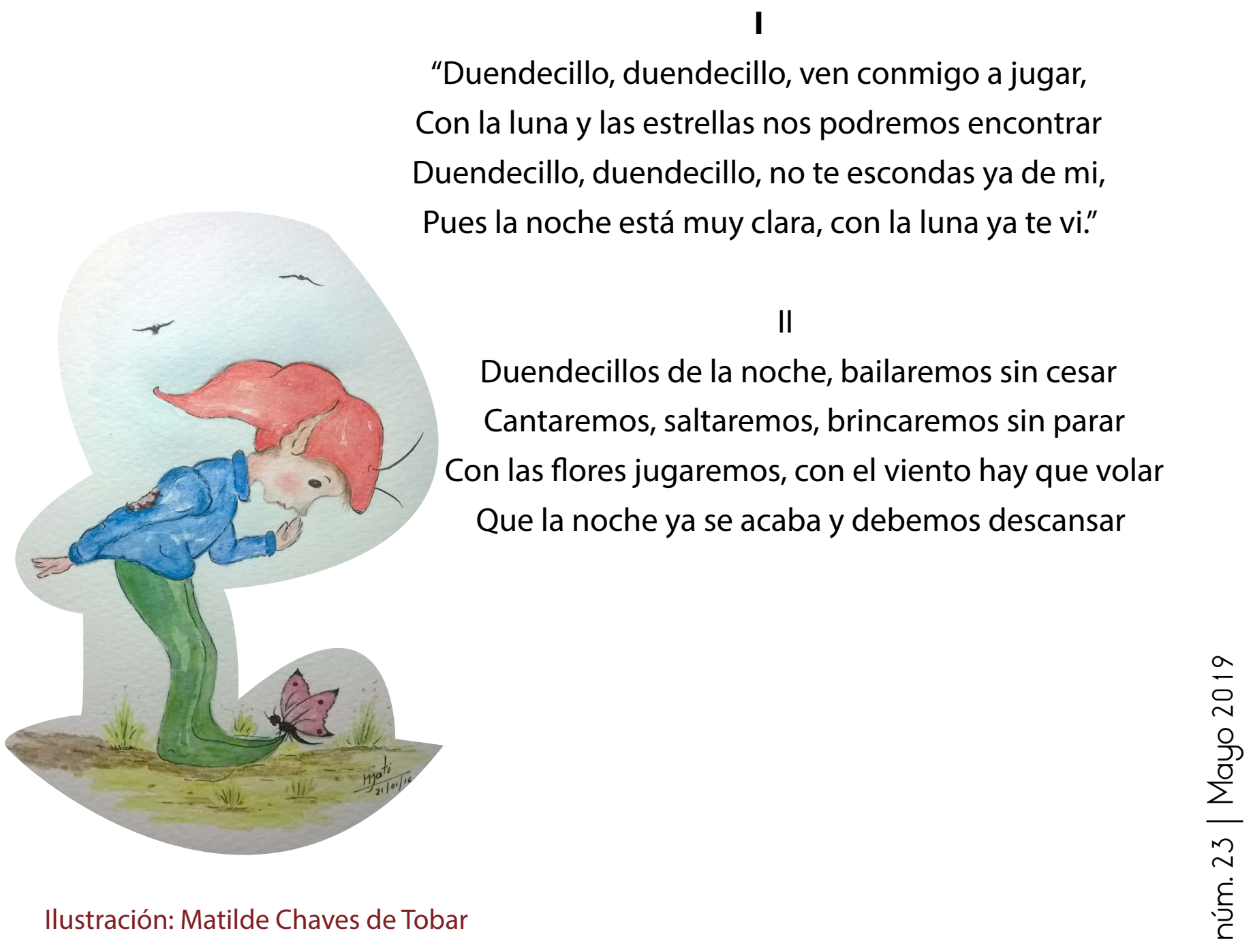




\section{"La Alegría de Cantar" \\ Natide Chaves de Tobar}

\section{Duendecillo}

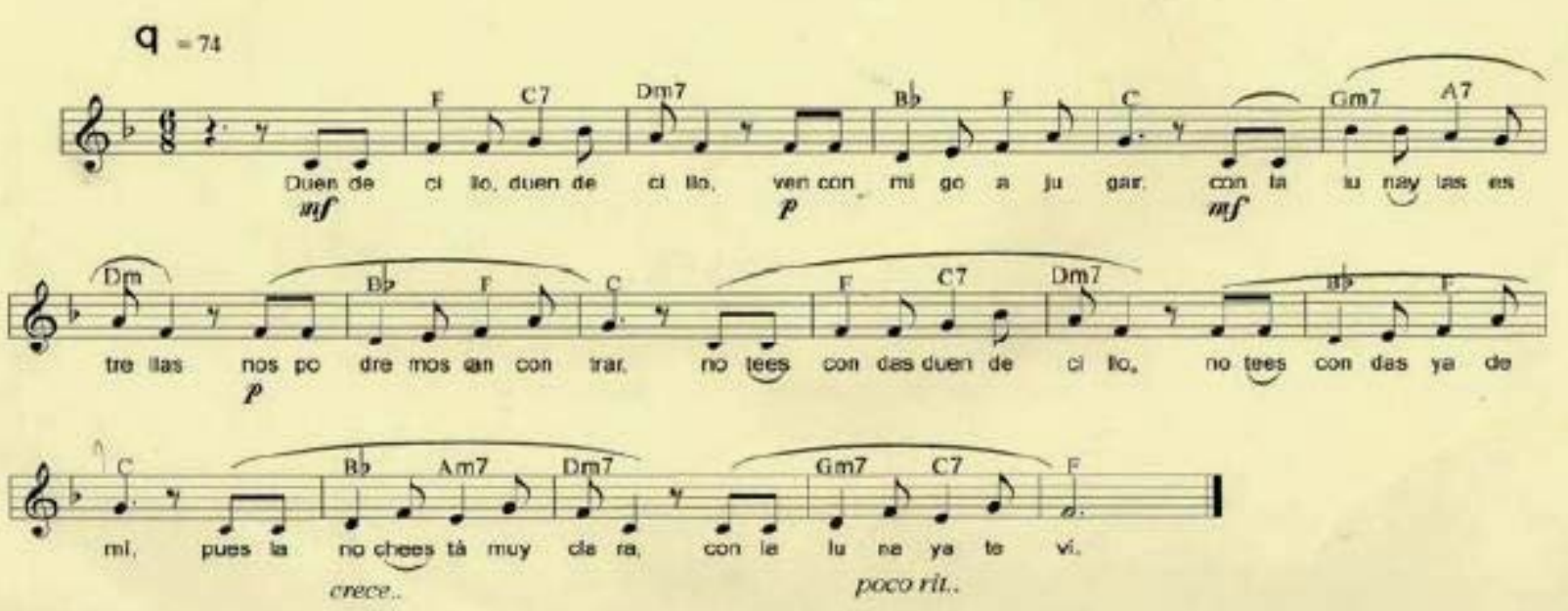

(y salen de debajo de los hongos, muy alegres y bailan con La niña, y las hadas todos juntos al son de la música.)

El narrador: LOS GNOMOS son los Hombrecitos de barba que custodian los tesoros escondidos en los bosques, así como los enanos son los mineros de las montañas.

Aquí suena el piano, con la obra "El gnomo" de Tchaikovky

Al terminar el baile y el canto, el duendecillo de la picardía le dice a la niña: Y dime, cómo nos has encontrado? Pequeña niña del bosque?

- La niña: Solo lo he deseado y vuestro amigo el gnomo serio me ha guiado hacia vosotros.

- Y el gnomo trabajador dice: Que alegría nos has dado al venir al bosque, sabes tú que nosotros trabajamos de noche? 
- La niña: De noche, pero si de noche debemos dormir j!!

Ah!!!! Sí dormir, eso es, dormir j!! Dormir j!!, Interrumpe el gnomo dormilón, Ah ¡! Que sueño ¡!!

- El Gnomo trabajador, le responde: “Calla perezoso ¡!! Que tú, en lugar de dormir, tienes que ayudar $\mathrm{j}$ !

- Y el Gnomo del sueño, dice a la niña: Pequeña niña del bosque ya es hora de que estés en vuestra cama durmiendo, porque mañana debéis madrugar.

- La niña: Si, si, es cierto, pero antes me gustará bailar y cantar con vosotros una última canción antes de la salida del sol, para despedirnos.

- Siiii, responden todos y al son de la música, todos bailan y poco a poco se van de nuevo a sus sitios.

\section{LA MEDIALUNA}

Letra. F. García Lorca-Música: Juan Felipe Restrepo

La luna va por el agua, está el cielo tranquilo

Va cegando lentamente el temblor viejo del río,

Mientras una rama joven, la toma por espejito.

El agua toca su tambor de plata (bis)

Los árboles tejen el viento y las rosas lo tiñen de perfume

Una araña inmensa hace a la luna estrella.

Cantemos juntos a la luna loca (bis)

La noche nos ríe contenta, las flores la llenan de perfume

Adiós que llega pronto la madrugada. 


\section{LA MEDIA LUNA}

Tranquilo / dulce. Ad Libitum

Texto: García Lorca
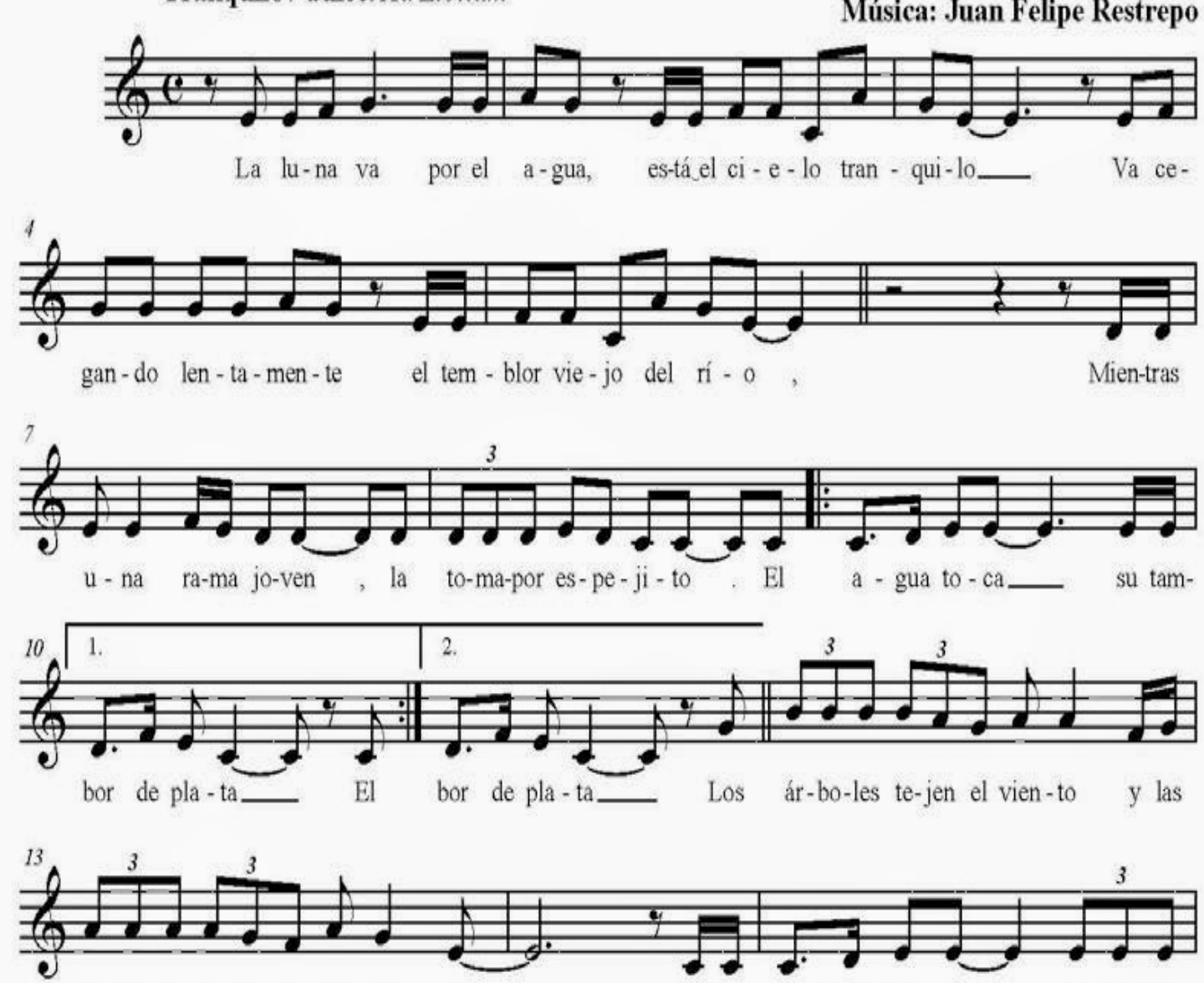

ro sas lo ti-ñen de per - fu - me__ U-na_a - ra - ña in-men sa__ ha-ce_a la

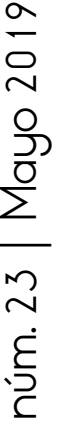
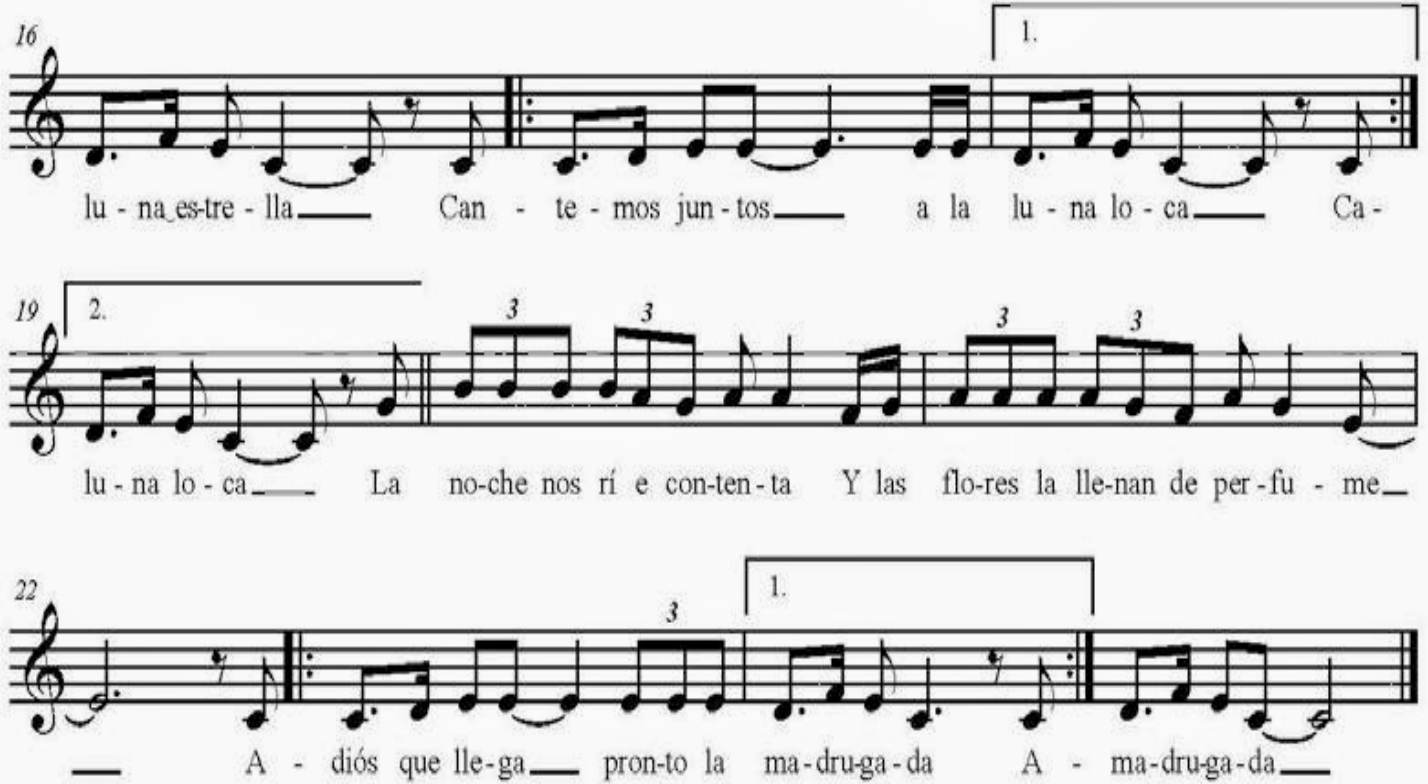
Las hadas vuelven al libro que el gnomo serio custodia y los gnomos se meten a sus refugios, debajo de los hongos y en los troncos de los árboles. La niña corre a su casa y la magia del gran libro volverá en la siguiente noche.

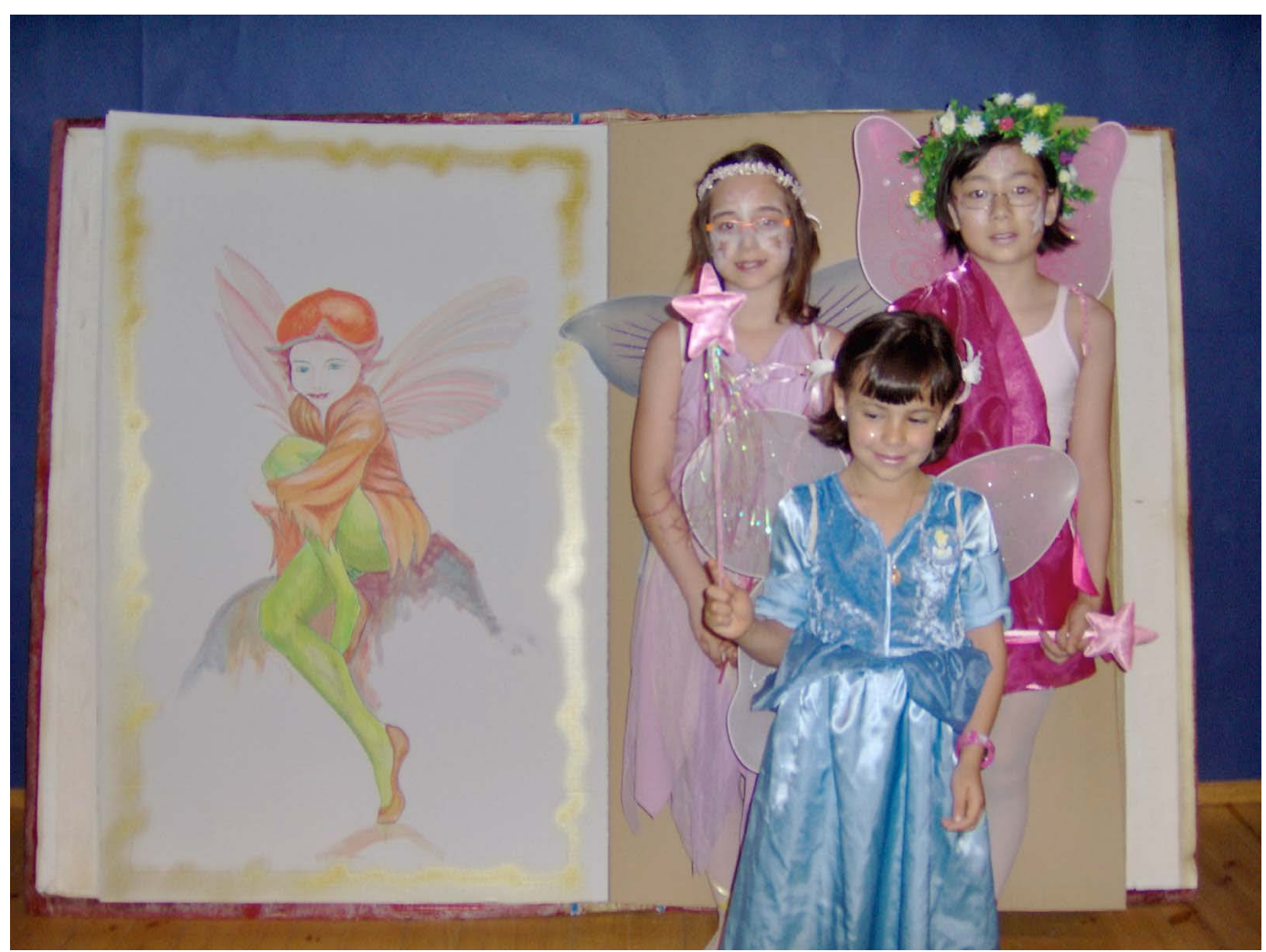

Alumnas de la Escuela Hispánica de Música 2008 Santa Marta de Tormes - Salamanca - España Ilustraciones del Libro: Javier Tobar Gómez

Estrenada en el Auditorio de Caja Duero - Santa Marta de Tormes - Salamanca España,

el 24 de Junio de 2008 